\title{
FRONTAL RESISTANCE COEFFICIENT OF THE BUSES WITH THE DIFFERENT VENTILATION EQUIPMENT
}

\author{
Orest Voznyak $^{1}$ - Oleksandr Dovbush ${ }^{1}$ - Peter Kapalo ${ }^{2}$ - Mariusz Adamski ${ }^{3}$ - Florin Domnita ${ }^{4}-$ \\ Ciprian Bacotiu ${ }^{4}$
}

\begin{abstract}
${ }^{1}$ Lviv Polytechnic National University, Department of Heat and Gas Supply and Ventilation, St. Bandery 12, 79013 Lviv, Ukraine, e-mail: orest.voznyak@i.ua, dovbush.ol@gmail.com

${ }^{2}$ Technical University of Kosice, Faculty of Civil Engineering, Department of Technical Building Equipment, Vysokoskolska 4, 04200 Kosice, Slovakia, e-mail: peter.kapalo@tuke.sk

${ }^{3}$ Bialystok University of Technology, Faculty of Civil and Environmental Engineering 45E, Wiejska Street, 15-351

Bialystok, Poland, e-mail: mariusz.adamski@pb.edu.pl

${ }^{4}$ Technical University of Cluj-Napoca, Building Services Faculty, Department of Building Services Engineering, 21 Decembrie 1989 Boulevard 128-130, 400604 Cluj-Napoca, Romania, e-mail: florin.domnita@insta.utcluj.ro
\end{abstract}

\begin{tabular}{|c|c|}
\hline ARTICLE INFO & Abstract: \\
\hline $\begin{array}{l}\text { Article history: } \\
\text { Received: } 04.04 .2019 . \\
\text { Received in revised form: } 31.05 .2021 . \\
\text { Accepted: } 03.06 .2021 .\end{array}$ & \multirow{8}{*}{$\begin{array}{l}\text { The article presents the results of the investigation of the influence } \\
\text { of natural and mechanical ventilation in a passenger compartment } \\
\text { and in a driver's compartment on the air flow around the bus. The } \\
\text { experimental research was carried out in aerodynamic tunnels. } \\
\text { Based on the measurements, the air velocities distribution in the } \\
\text { boundary layer was determined. Furthermore, the effect of natural } \\
\text { ventilation of the interior space on the thickness of the air } \\
\text { boundary layer was analysed. The results are presented in the form } \\
\text { of distribution diagram and analytical dependencies. The aim of } \\
\text { this research was to define the thickness of the boundary layer } \\
\text { when the air flows through a vehicle model. }\end{array}$} \\
\hline Keywords: & \\
\hline Boundary layer & \\
\hline Air flow & \\
\hline Aerodynamic tunnel & \\
\hline Ventilation & \\
\hline Boundary layer thickness & \\
\hline DOI: https://doi.org/10.30765/er.1443 & \\
\hline
\end{tabular}

\section{Introduction}

Along with the rise in oil prices, there has been an increasing emphasis on different forms of energy-saving designs in automotive industry. If a vehicle's speed increases, the aerodynamic drag also increases. The reduction of fuel consumption can be achieved by reduction of aerodynamic drag. This study [1] provides the theoretical basis for drag reduction and energy saving for a truck.

The frontal resistance of a bus depends on its aerodynamic shape. The magnitude of aerodynamic drag is characterized by the coefficient of aerodynamic drag $C_{x}$. According to Schlichting [2], the natural ventilation from side windows of a vehicle affects the overall aerodynamic drag of the vehicle, while the ventilation through the vehicle's side windows increases its boundary thickness.

The increase of intercity and tourist bus transportation results in an increase in the share of the movement of such modes of buses, in which their aerodynamic properties become significant. The important aerodynamic characteristic of a bus is its dimensionless coefficient of frontal resistance $C_{x}$, which represents the ratio of the aerodynamic frontal resistance to the dynamic force resulting from the action of the air flow. This air flow is characterized by the Reynolds number values $[3,4,5,6]$.

While designing new buses, special attention is paid to reducing frontal resistance, which affects fuel efficiency.

For evaluation of the economical index of the fuel consumption of the bus, the frontal resistance force $P_{x}$ shows some interest in the coefficient $C_{x}$ of frontal resistance. This magnitude depends on the streamlines body, the shape, and thickness of the air boundary layer. Besides that, the air exchange through bus ventilation units (intake air and exhaust air) has an influence on the frontal resistance of a bus in motion, which results in

\footnotetext{
* Corresponding author

E-mail address: mariusz.adamski@pb.edu.pl
} 
its increasing. In this paper, the coefficient $C_{x}$ of frontal resistance is experimentally determined in a wind tunnel because the analytic calculation of this coefficient $C_{x}$ is complicated.

\section{Materials and methods}

The experimental measurements were performed on the bus model such as LAZ - 42021 (Figure 1) produced by Lviv Automobile Factory in Ukraine. This bus is $9.7 \mathrm{~m}$ in length, $2.5 \mathrm{~m}$ in width, 3,008 $\mathrm{m}$ in height, does $90 \mathrm{~km} / \mathrm{h}$ of the maximum speed and has 13.63 tonnes in its weight [7]. In this bus, the driver's seat is separated from the passenger compartment.

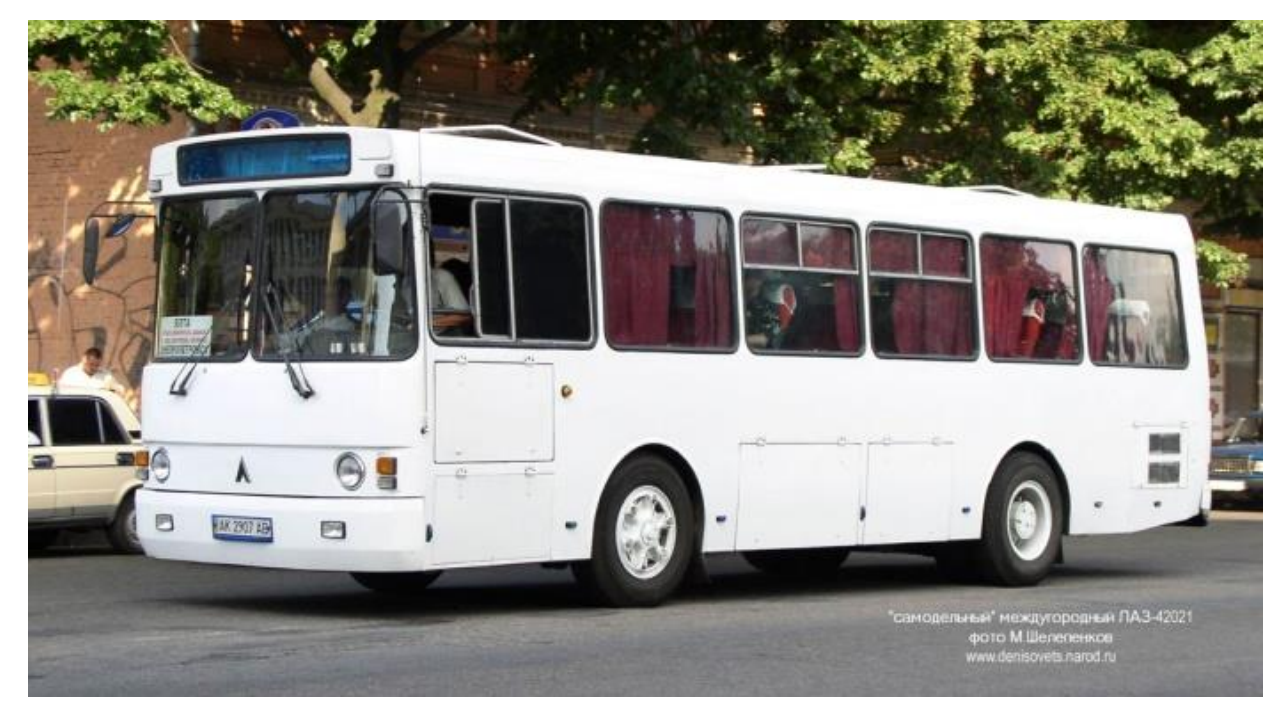

Figure 1. Bus LAZ - 42021. Photo by: Shelepenkov [8].

The basic ventilation schemes of buses used for different purposes are described below. For tourist buses, a traditional ventilation system is suitable which uses the individual air distribution units. Therefore, the additional equipment that secures the variable air supply into a bus is reasonable (Figure 2) [9]. This gives the possibility for dynamic control of the microclimate in a passenger compartment $[10,11,12,13]$. After the installation of this equipment, the periodical change of the supply of air jets velocity is secured due to the changeable amount of intake air in each pipe section.

For the intercity buses, the installation of three ventilation hatches is recommended because this solution supplies and extracts air from different sections (Figure 3) [14]. This option has some advantages in comparison to the traditional ventilation options:

- the total airflow rate is higher due to the existence of two sections in these units for intake and exhaust air;
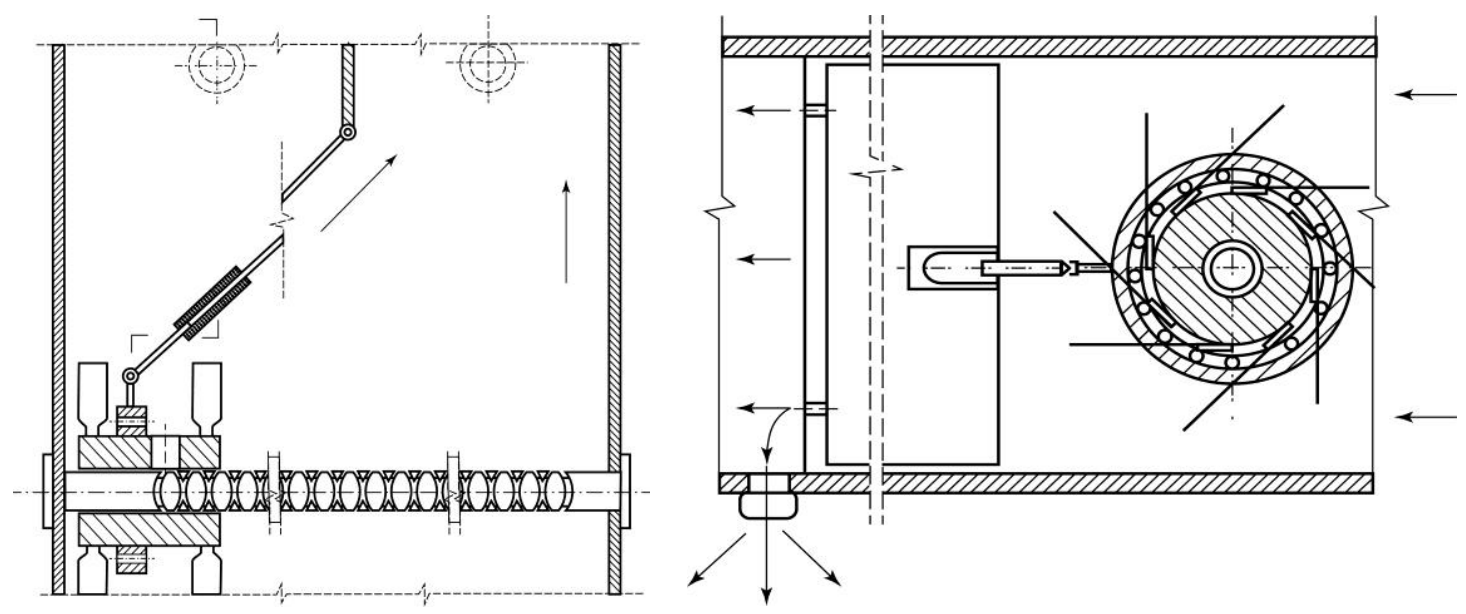

Figure 2. Ventilation unit for variable air supply into the bus. 
- the air jets spread on the internal surface of the bus, improving the comfort conditions [15].
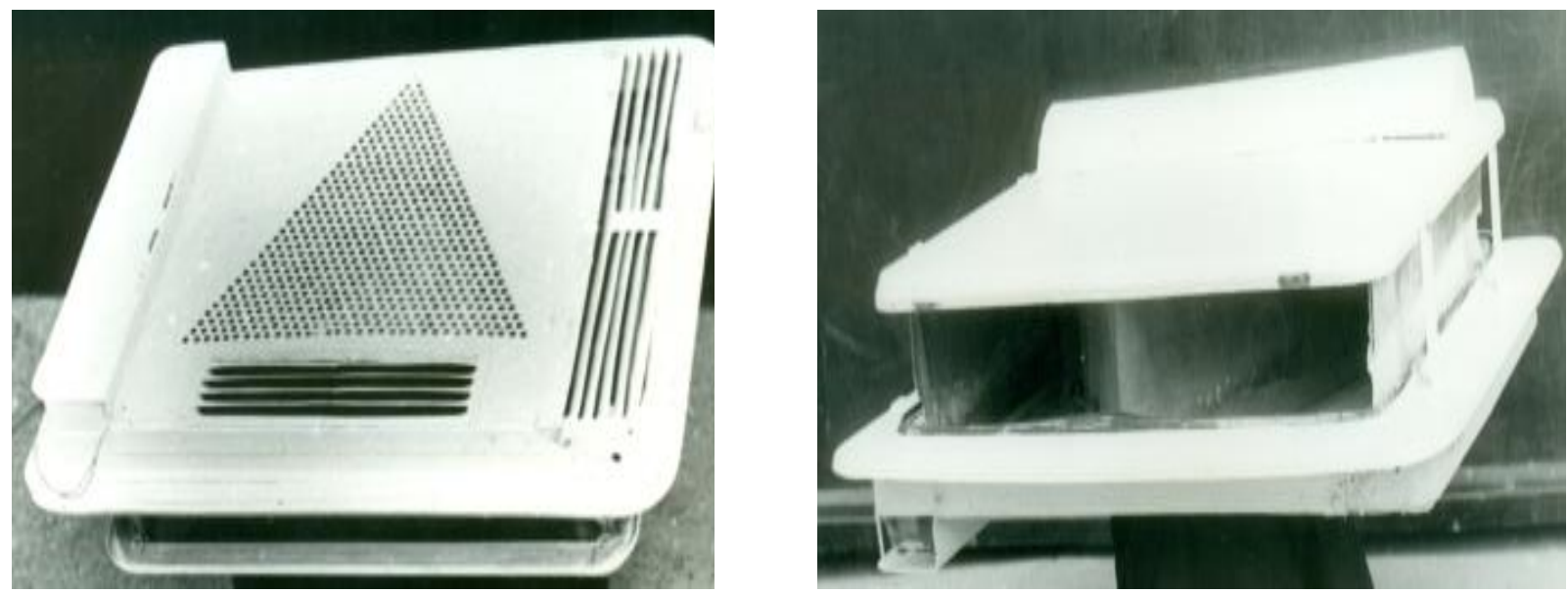

Figure 3. Combined ventilation hatch.

For the city buses, the mechanical ventilation is suitable due to the ventilation units. This equipment includes a ventilation hatch with a fan added and placed in the hatch exhausted section (Figure 4). The fan works and ensures air supply when the bus stops or moves at the low speed.

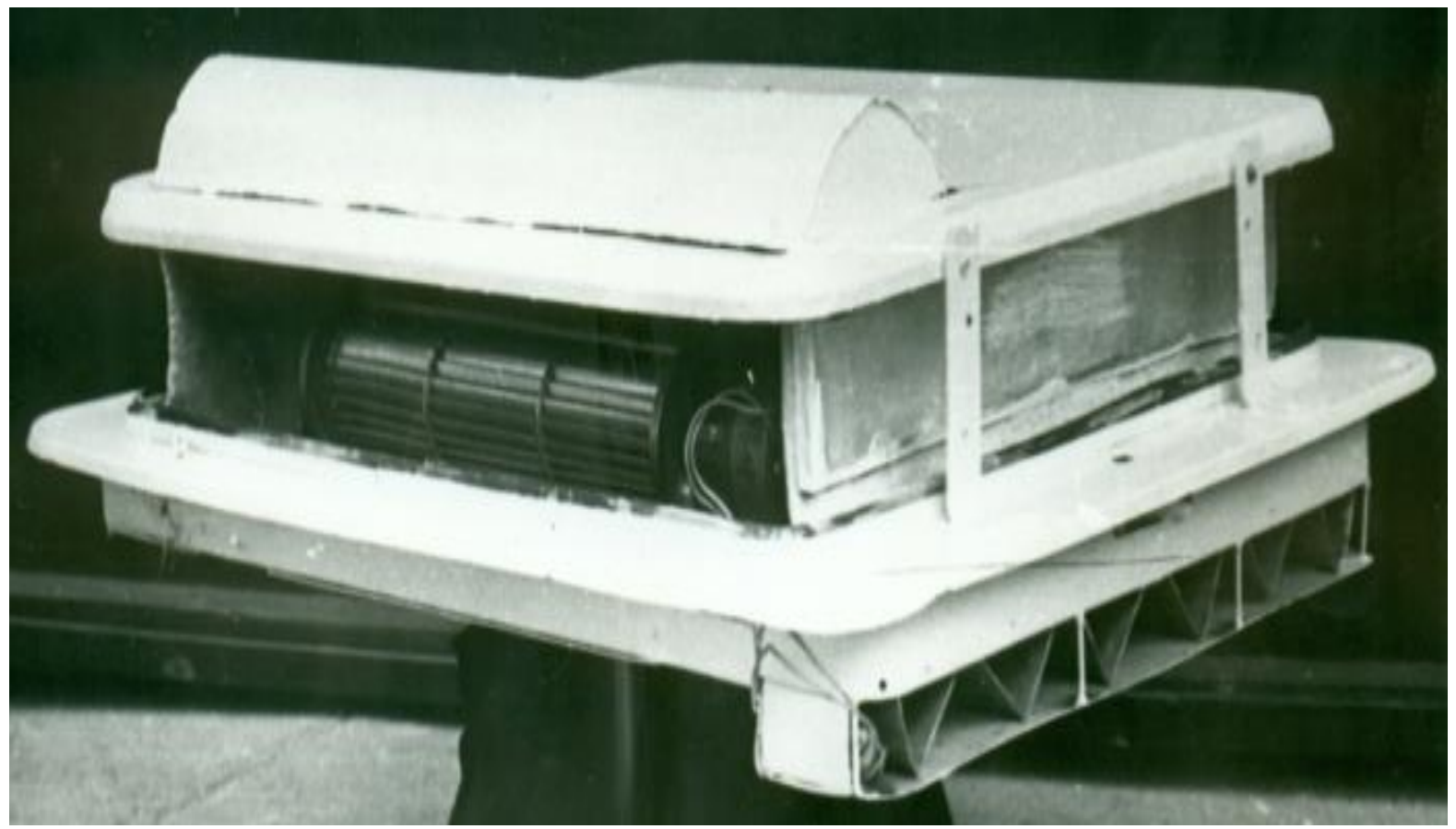

Figure 4. Ventilation unit.

This study shows the experimental investigations that were carried out in the wind tunnel (Figure 5) in order to determine the coefficient of the frontal resistance for the bus model that is equipped with three types of ventilation units described above. 


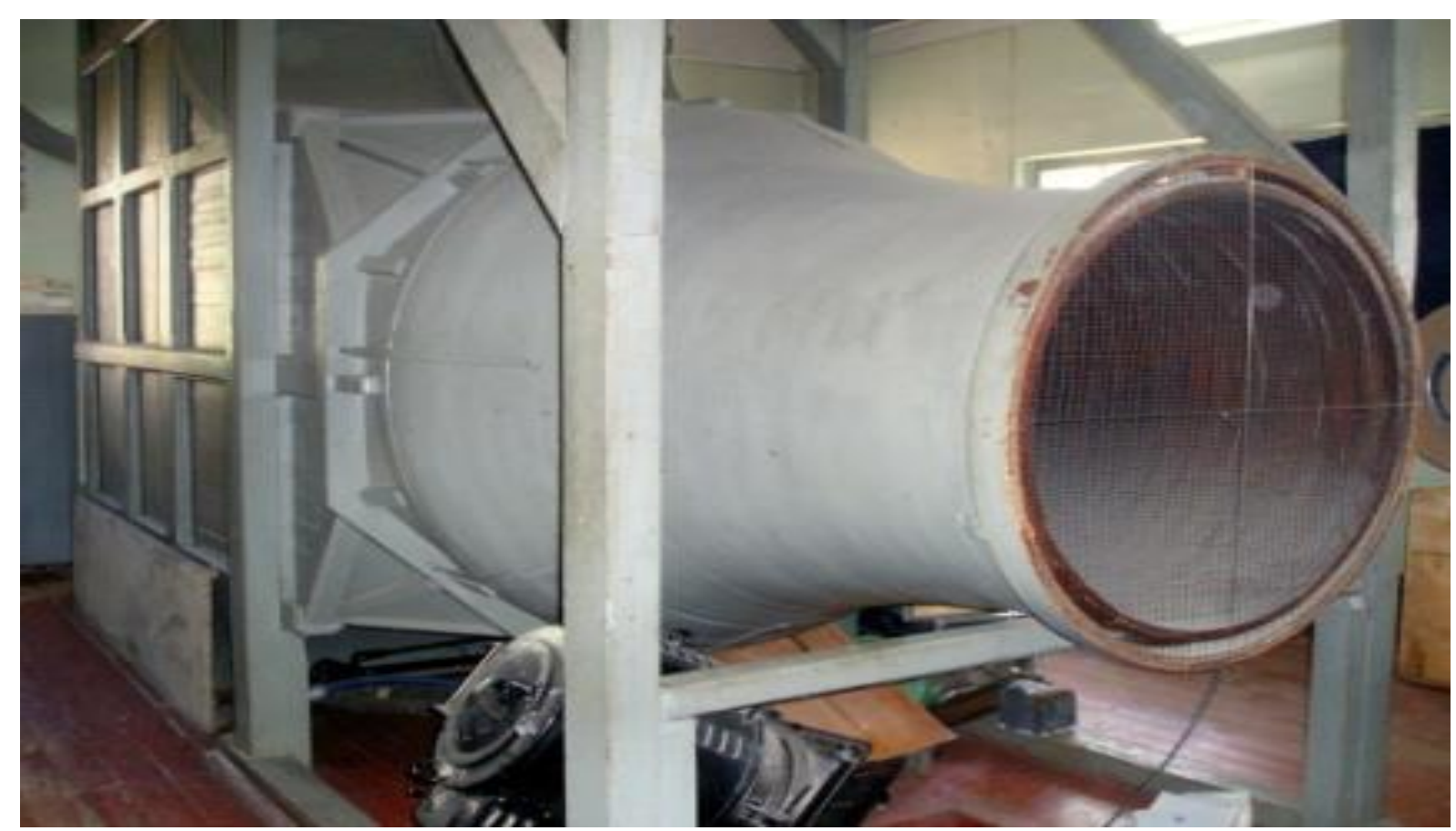

Figure 5. The working part of an aerodynamic tunnel.

\section{The results and discussion}

3.1 An air boundary layer investigation at the streamlines body of the bus in the aerodynamic tunnel

Different modes for the prevention of boundary layer separation are known. One of them is sucking off the air from the boundary layer. It should be noted that the air supply through small windows, placed in the central and stern part of the bus, could be considered as sucking off the air from the boundary layer. This factor results in improving streamlines body along with a decrease in the boundary layer thickness.

The volumetric airflow rate in the boundary layer near small windows in absence of ventilation, with height $h$ (Figure 6), is determined from the relation:

$$
L_{1}=V_{a} \cdot h \cdot \delta_{1}
$$

By this, the average velocity $V_{a}$ near the small windows is assumed as a constant and is presented as follows:

$$
V_{a}=\frac{1}{\delta_{1}} \int_{0}^{\delta_{1}} V(y) d y
$$

Besides that, we assumed that the distribution of velocities in the boundary layer, in absence of the air supply is described by the same functional dependence on powering form:

$$
V(y)=\alpha \cdot y^{n}
$$




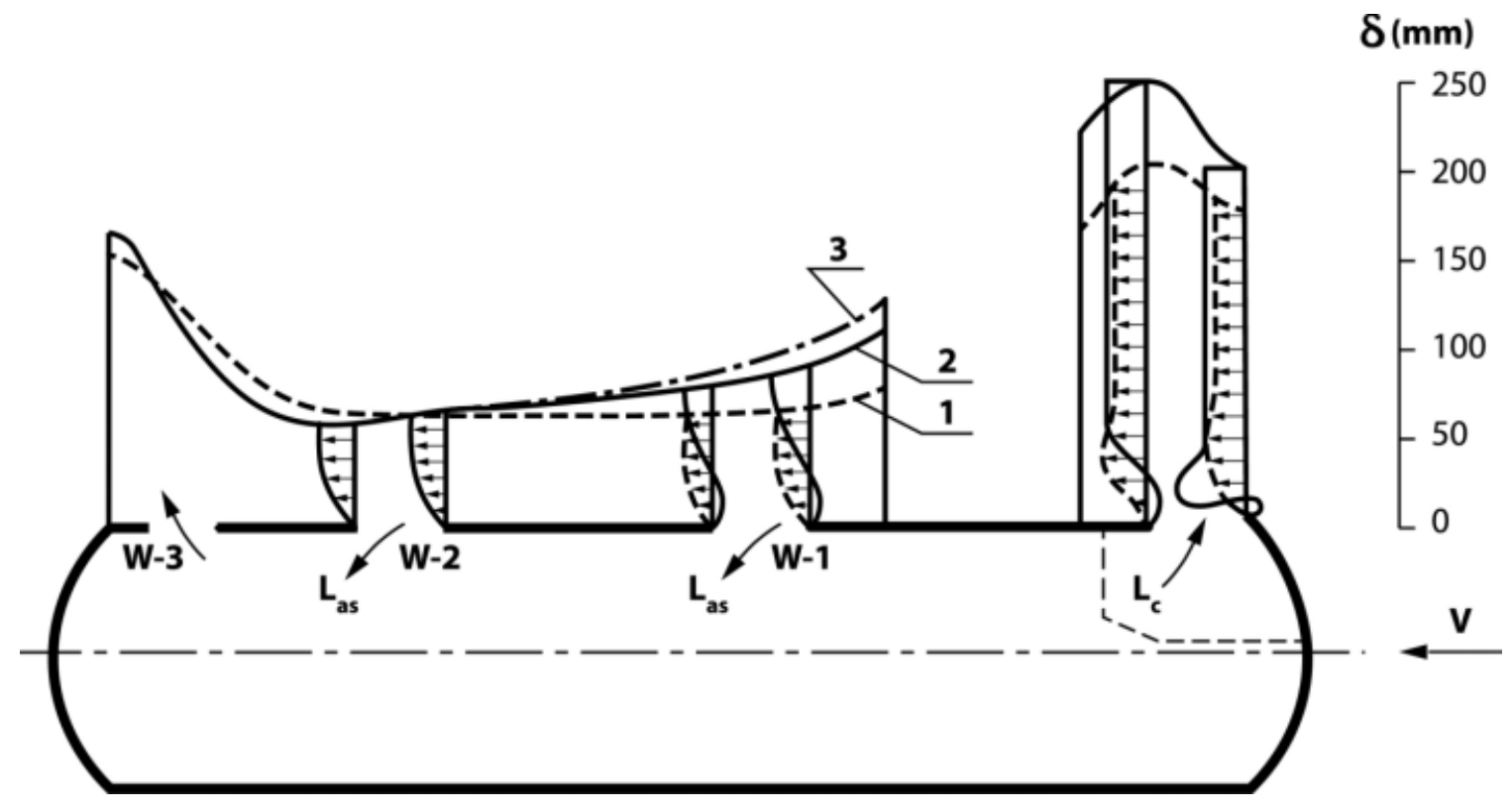

Figure 6. Distribution of air velocity and the boundary layer thickness at the bus streamlines at the height of window centres: 1 - all the windows are shut; 2 - all the windows are open; 3 - all the windows are shut, except for the first window.

In this equation, the power exponent $n$ and the proportion coefficient $\alpha$ are experimental constants. Proceeding from this, the magnitude of the average velocity is:

$$
V_{a}=\frac{1}{\delta_{1}} \int_{0}^{\delta_{1}} \alpha \cdot y^{n} d y=\frac{\alpha}{n+1} \delta_{1}^{n}
$$

Considering formula (1), the volumetric airflow rate in the boundary layer is:

$$
L_{1}=\frac{\alpha}{n+1} \delta_{1}^{n+1} \cdot h
$$

Further, we assumed that the air supply movement would be observed in the boundary layer with the thickness of $\delta_{2}=\beta \delta_{1}$. In this case, the volumetric airflow rate is:

$$
L_{2}=\frac{\alpha}{n+1}\left(\beta \delta_{1}\right)^{n+1} \cdot h
$$

Considering $L_{2}=L_{l}-L_{a s}$ where $L_{a s}$ is air supply volume, we obtain:

$$
\frac{\alpha}{n+1}\left(\beta \delta_{1}\right)^{n+1} \cdot h=\frac{\alpha}{n+1} \delta_{1}^{n+1} \cdot h-L_{a s}
$$

Thereby the relation of the boundary layer thickness is:

$$
\beta=\left(1-\frac{L_{a s}(n+1)}{\delta_{1}^{n+1} \cdot \alpha h}\right)^{\frac{1}{n+1}}
$$

By exhausting the air through the small windows in a stern part of the bus (window 3) and particularly through the driver's one, the exhausted air from the passengers' compartment is added in the boundary layer. 
Due to this factor, the boundary layer thickness increases. Also, the streamlines body is deteriorated and the coefficient of resistance increases.

It should be noted that the external undisturbed flow is distorted appreciably, which becomes very significant. This is the result of reversing its flow lines from the surface [16]. The boundary layer separation causes particularly sudden distortion and the streamlines body stops being smooth. By this, the boundary layer thickness increases, and as a result the direct solution of the boundary layer equations is impossible [16]. In this case, the influence of the boundary layer reverse on the streamlines body must be considered, and the results of the experimental investigations of the air velocities distribution are used.

Velocity distribution in the boundary layer near a driver's window is described by complicated functional dependence [16]. Thereby, for simplification we used the following formula for the average air velocity:

$$
V_{a}=\frac{1}{N} \sum_{i=1}^{N} V_{i}
$$

where $V_{i}$ is airflow rate in the $i$ boundary layer and $N$ is number of experimental points. The airflow rate in the boundary layer in the absence of the air exhausting from the driver's window with height $H$ by considering formulas (1) and (9), is:

$$
L_{1}=H \delta_{1} \frac{1}{N} \sum_{i=1}^{N} V_{i}
$$

By analogy, the relation of the boundary layer thickness in the presence or absence of the exhausting air equals $\beta$ with $\delta_{2} / \delta_{1}$. Thus, the airflow rate in the boundary layer becomes:

$$
L_{2}=\beta H \delta_{1} \frac{1}{N} \sum_{j=1}^{N} V_{j}
$$

Considering that $L_{2}=L_{1}+L_{e}$, where $L_{e}$ is exhausted airflow rate, we obtain:

$$
\beta H \delta_{1} \frac{1}{N} \sum_{j=1}^{N} V_{j}=H \delta_{1} \frac{1}{N} \sum_{i=1}^{N} V_{i}+L_{e}
$$

Thereby, the relation of boundary layer thickness in the presence or absence of exhausted air is:

$$
\beta=\frac{H \delta_{1} \frac{1}{N} \sum_{i=1}^{N} V_{i}+L_{e}}{H \delta_{1} \frac{1}{N} \sum_{j=1}^{N} V_{j}}
$$

For calculation of the boundary layer thickness near the small windows and driver's windows, the experimental aerodynamic research was carried out.

The air boundary layer at the bus streamlines body was studied in the presence or absence of the exhausted air through the small windows and through the driver's window. The distribution of velocities in the boundary layer was explored through a needle probe, mounted on a special support. The results obtained are presented in Figure 6 and Figure 9 which are horizontal cross-sections. By this distribution of the velocities in pressure reduced zone (air supply through windows 1 and 2), by considering $n=1 / 7$ and $\alpha=27.17$ in relation (3), this gives the following equation:

$$
V(y)=27.17 \cdot y^{\frac{1}{7}}
$$

This equation is pseudo-powering dependence [16] (window 1) in the pressure increased zone (the consequence of the air exchange due to the influence of the driver's window). Window 1 realizes the air supply, 
but it is under the influence of air stream that is exhausted through the driver's window. As a result, window 1 is in the zone of pressure with positive gradient. It has a pseudo-powering dependence of the velocity distribution. The air boundary layer thickness in this zone increases.

The results of these investigations have shown that the boundary layer thickness is approximately constant near the moving small windows, which had been assumed.

Comparing the calculation for the natural ventilation in the bus passengers bus with known methods [16] and by relations (8) and (13) it should be noted that the same results are obtained: the boundary layer thickness decreases about $8 \%$ at the air supply movement through small windows and it increases by $17 \%$ at the movement of the air exhaust through the driver's window. In conclusion, there is the similarity between calculations and experiments.

\subsection{Influence of the ventilation and air conditioning system on the frontal resistance of the bus in motion}

In order to investigate the different influence of ventilation and air conditioning equipment on the determination of the coefficient of frontal resistance of the bus, the experimental aerodynamic research was carried out. The investigation was conducted in two-circuit aerodynamic tunnels with the size of opened working section $d \times D=1,000 \mathrm{~mm} \times 1,200 \mathrm{~mm}$ at Lviv Polytechnic National University, Ukraine (Figure 5). The empty bus model with different ventilation equipment was the exact copy of the bus LAZ-42021 in scale 1:15 (Figure 7).

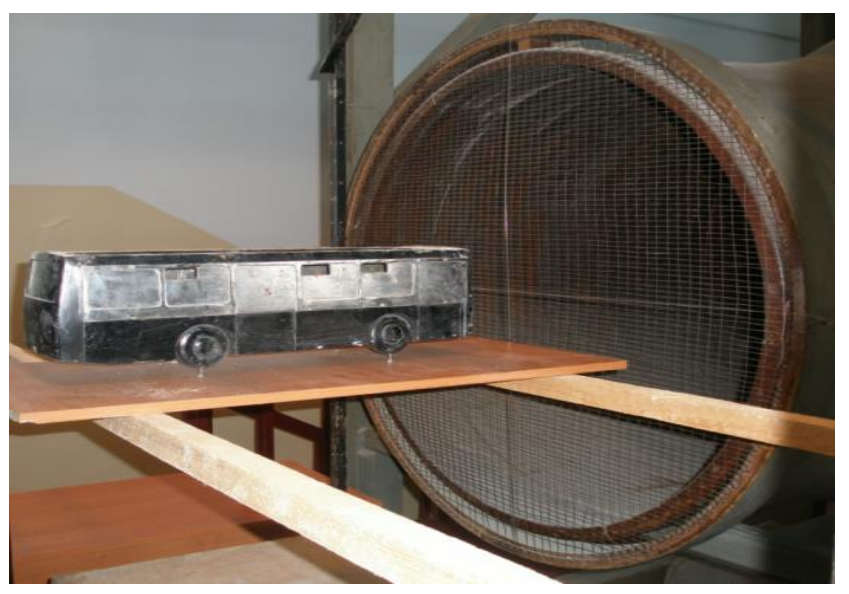

a)

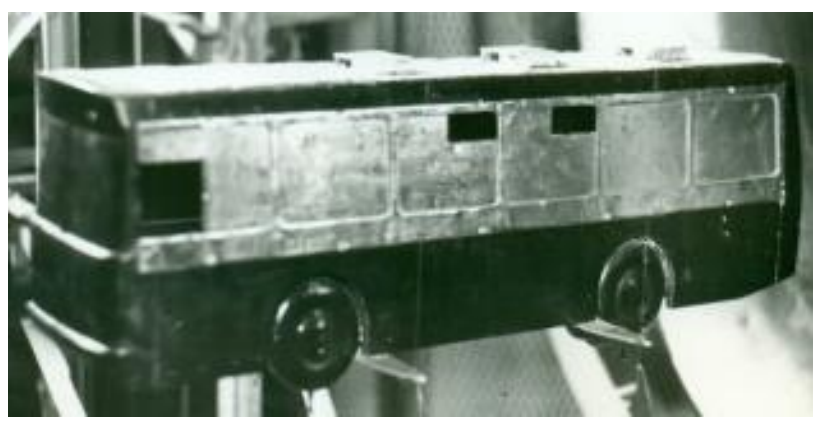

b)

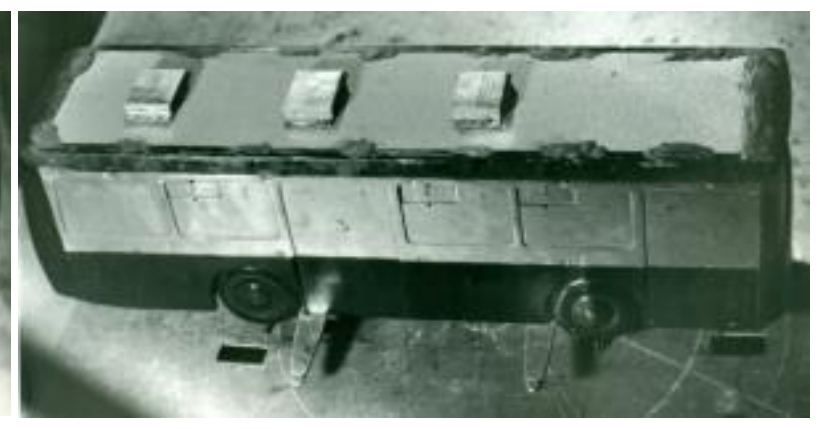

c)

Figure 7. Empty bus model in the wind tunnel.

Determination of the frontal resistance force was realized by direct measurement due to the six-component weight with a flexible hanging unit.

On the bus in movement, there are forces and moments of forces that appear because of the interaction of the bus with the air. They are reduced to the aerodynamic force $P_{x}$ (applied in the metacentre of pressure) and to the resulting moment $M$ (relative to the bus centre of gravity). 
Figure 8 shows the forces and moments acting on the bus, with the axis $X$ directed along the longitudinal axis of the bus, the axis $Y$ - perpendicular to it in the horizontal plane and the axis $Z$ - perpendicular to it in the vertical plane. Taking into account the projections of these forces on the coordinate axis, in the study of the pulling-speed properties and fuel efficiency of the bus the interest is on the frontal resistance $P_{x}$, the component of the resulting force, which is parallel to the direction of the undisturbed flow.

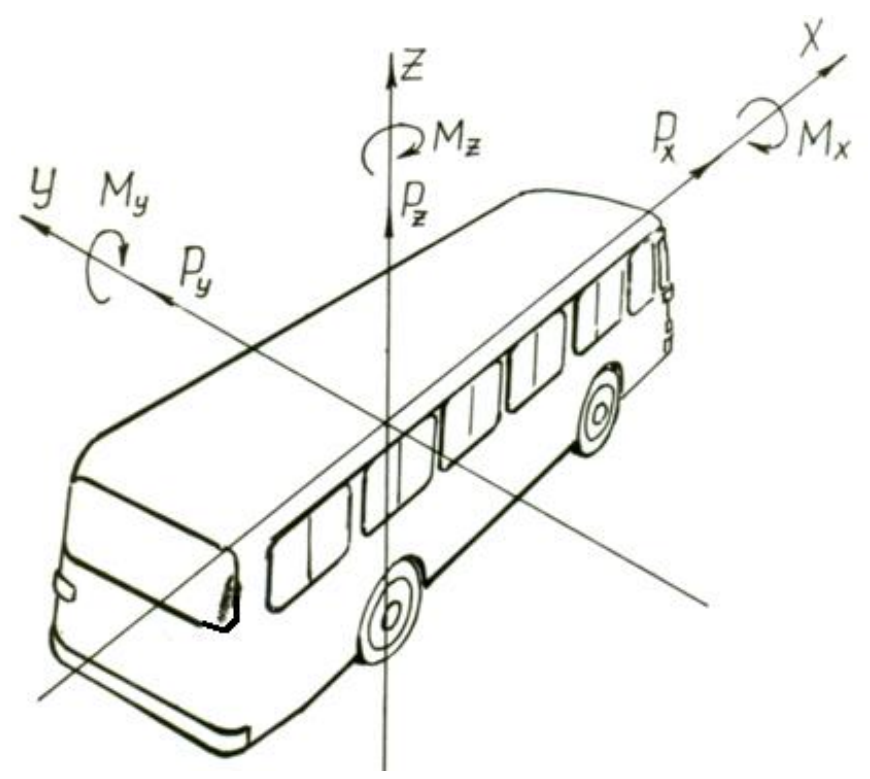

Figure 8. Forces and moments of forces that act on the bus in movement.

From the analysis of the dimensions, it follows that there is the dimensionless coefficient of aerodynamic resistance to which it is necessary to divide this force into $F_{m}$ - the frontal area of the bus (the middle section) and $P_{d y n}$ - the dynamic pressure of the airflow. Based on this, the dimensionless coefficient of frontal resistance is:

$$
C_{x}=\frac{P_{x}}{P_{\partial u н} \cdot F_{m}}
$$

The value of $C_{x}$ depends on the streamlines body of the air flow and on the shape and thickness of the boundary layer of the air. Due to the friction, the air speed is much smaller than at a certain distance from the surface of the bus.

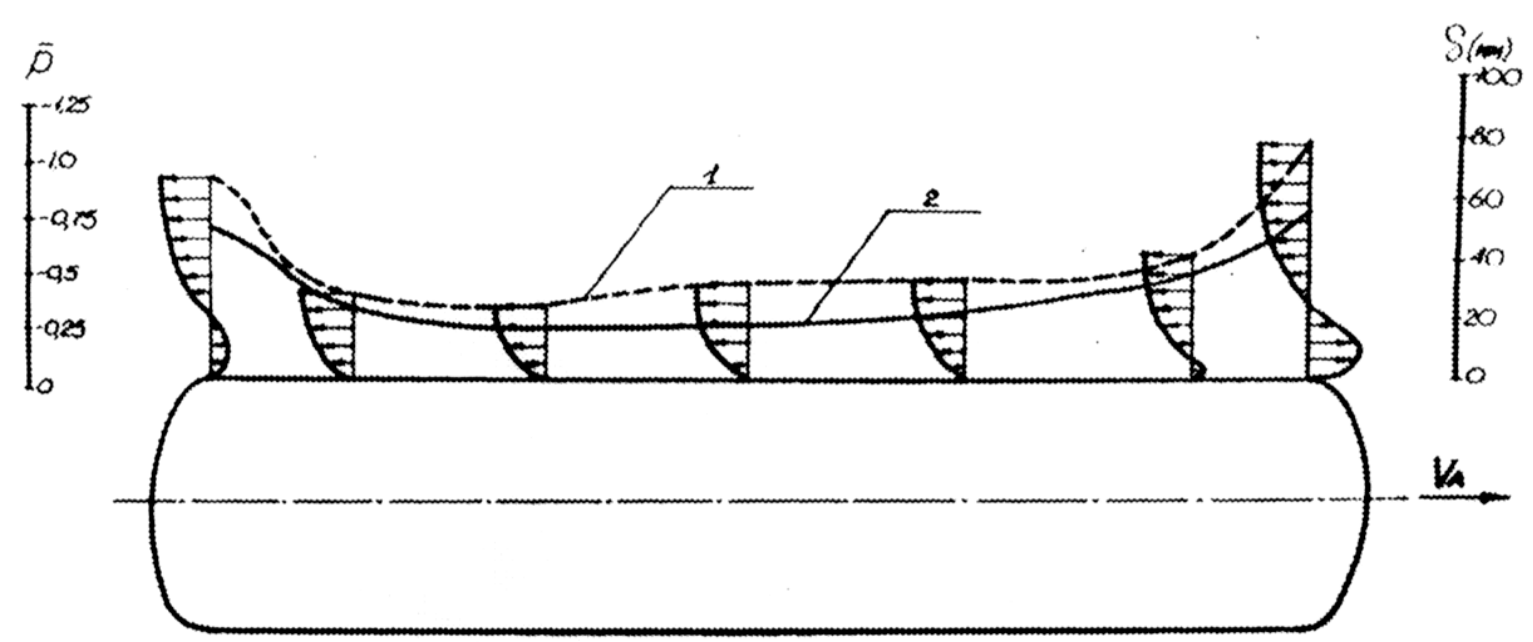

Figure 9. Velocity (line 1) and pressure (line 2) distribution in the boundary layer of the bus. 
The measurement was made by the known methods according to Gorlin and Slezinger [16] and Voznyak [17] at air stream velocities between $19 \mathrm{~m} / \mathrm{s}$ and $25 \mathrm{~m} / \mathrm{s}$ that corresponds to $\operatorname{Re}=2.01 \times 10^{6} \div 2.65 \times 10^{6}$. The experimental results are completely verified [11].

The air boundary layer and the frontal resistance coefficient at the streamlines body of the bus were studied in the presence or absence of exhausting air through different ventilation and air conditioning equipment placed in different zones of the bus surface. The distribution of the velocities in the boundary layer was explored through a needle probe mounted on a special support. The results obtained are presented on Figure 9.

Window 1 provides the air supply, but it is under the influence of the air stream that is exhausted through the driver's window. As a result, the window 1 is in the zone of pressure with positive gradient, the thickness of the air boundary layer increases in this zone and so does the coefficient of the frontal resistance of the bus in motion. At the investigation in a wind tunnel with the bus model, the ground influence on the streamlines body was considered. For the purpose of modelling the road, hard screens were used. The models were located on the distance of $17 \mathrm{~mm}$ from the wheels, bottom to the screen. The experimental results of the coefficient $C_{x}$ of the frontal resistance of the bus models with different ventilation equipment are presented in Table 1.

The data presented in Table 1 proves that the bus, equipped with natural ventilation units, leads to the increase of the coefficient $C_{x}$ of the frontal resistance more than the solution with mechanical ventilation units. Thus, using natural ventilation equipment hatches, small windows, the driver's window is not reasonable, because the frontal resistance increases about $10 \%$.

Table 1. Coefficient of the frontal resistance of the bus in motion at the different ventilation schemes.

\begin{tabular}{|c|c|c|}
\hline Ventilation scheme & $\begin{array}{l}\text { Resistance } \\
\text { coefficient } \\
\qquad C_{x}\end{array}$ & $\begin{array}{c}\text { Increase } \\
{[\%]}\end{array}$ \\
\hline \multicolumn{3}{|l|}{ Natural ventilation is absent } \\
\hline $\begin{array}{l}\text { 1. Small windows are closed, hatches are } \\
\text { absent. }\end{array}$ & 0.672 & 0.0 \\
\hline $\begin{array}{l}\text { 2. Three hatches and small windows are } \\
\text { closed }\end{array}$ & 0.678 & 0.8 \\
\hline \multicolumn{3}{|l|}{ Natural ventilation is present } \\
\hline $\begin{array}{l}\text { 3. Small windows are open, hatches are } \\
\text { absent, the driver's window is closed. }\end{array}$ & 0.692 & 3.0 \\
\hline $\begin{array}{l}\text { 4. All the windows are open, hatches are } \\
\text { absent. }\end{array}$ & 0.717 & 6.7 \\
\hline $\begin{array}{l}\text { 5. Hatches and small windows are open, the } \\
\text { driver's window is closed. }\end{array}$ & 0.713 & 6.1 \\
\hline $\begin{array}{l}\text { 6. Hatches combined are open, all the } \\
\text { windows are closed. }\end{array}$ & 0.707 & 5.2 \\
\hline $\begin{array}{l}\text { 7. Hatches combined are open, small } \\
\text { windows are closed; the driver's window is } \\
\text { open halfway down. }\end{array}$ & 0.717 & 6.7 \\
\hline $\begin{array}{l}\text { 8. Hatches combined are open, small } \\
\text { windows are closed; the driver's window is } \\
\text { fully open. }\end{array}$ & 0.735 & 9.4 \\
\hline \multicolumn{3}{|l|}{ Mechanical ventilation is present } \\
\hline $\begin{array}{l}\text { 9. Air supply unit is located on the roof in the } \\
\text { central zone. }\end{array}$ & 0.698 & 3.9 \\
\hline $\begin{array}{l}\text { 10. Air supply unit is located on the roof in } \\
\text { the central zone, small windows are open, the } \\
\text { driver's window is closed, and hatches are } \\
\text { open. }\end{array}$ & 0.704 & 4.8 \\
\hline \multicolumn{3}{|c|}{ Air conditioning equipment set is located on the bus roof } \\
\hline 11. - in frontal part; & 0.678 & 0.9 \\
\hline 12. - in central part; & 0.698 & 3.7 \\
\hline 13. - in stern part. & 0.710 & 5.7 \\
\hline
\end{tabular}


Based on Voznyy and Luzinov [18] it is possible to conduct the quantitative assessment while considering the issue of the bus fuel consumption economy. In Table 2, the fuel consumption Q [1/100 km] at different speeds of the bus and its various frontal resistance coefficients are shown. As it can be seen from Table 2, when $C_{x}$ increases from 0.65 to 0.75 , the fuel consumption increases by $4 \%$ at $V_{a}=40 \mathrm{~km} / \mathrm{h}$ and by $8 \%$ at $V_{a}$ $=90 \mathrm{~km} / \mathrm{h}$. Based on the given data, mathematical processing of the results was performed and the empirical dependence $Q=f\left(C_{x} ; V_{a}\right)$ was established:

$$
Q=\left(0,8 C_{x}+0,55\right) \cdot V_{a}^{0.7}+2.5[1 / 100 \mathrm{~km}]
$$

with a relative error less than $8 \%$. With this formula, it is possible to carry out the necessary calculations with variable bus speeds, using the method of computer numerical integration. In table 2 the measurements are documented of the bus fuel flow rate, what is the value from the experimentally measured real bus.

Table 2. The bus fuel flow rate $Q$ measured [l/100km].

\begin{tabular}{|c|c|c|c|c|c|c|}
\hline Coefficient & \multicolumn{5}{|c|}{ The average velocity $V_{a}[\mathrm{~km} / \mathrm{h}]$} \\
\cline { 2 - 7 }$C_{x}$ & 40 & 50 & 60 & 70 & 80 & 90 \\
\hline 0.65 & 16.8 & 18.0 & 19.9 & 22.1 & 25.0 & 29.0 \\
\hline 0.70 & 17.1 & 18.5 & 20.5 & 22.9 & 26.0 & 30.1 \\
\hline 0.75 & 17.4 & 19.0 & 21.1 & 23.7 & 27.0 & 31.2 \\
\hline
\end{tabular}

The data from Table 1 and Table 2, as well as the equation (16) give an opportunity to quantify the fuel and the economic performance of the buses used for various purposes, equipped with different ventilation and air conditioning systems in the passenger compartments.

\section{Conclusion}

1. Based on this research, it can be concluded that if it is desirable to increase the air supply rate, the ventilation devices must be placed at the stern part of the bus, not at the front part. This measure improves a streamlines body during the bus movement and thus its economical index of the fuel consumption.

2. To design new bus models, taking into account their different purposes and the economical index of fuel consumption, the following is recommended:

-to separate the driver's window from the passengers compartment, which helps eliminating the harmful influence of the exhausted air coming through it;

-to design an additional ventilation system for the driver's compartment;

-to increase the air supply rate by using mechanical ventilation units and to place them at the front stem part of the bus;

-to use the hatches combined, which is effective concerning the airflow rate supply, as well as decrease the frontal resistance of the bus in motion;

-it is not reasonable to use small windows for the intercity and tourist buses.

3. These measures secure the needed airflow rate inside the passengers' compartment without increasing the frontal resistance of the bus in motion, considering the different types of a bus, and also keeping the economical index of the fuel consumption of the bus at the reasonable levels.

\section{References}

[1] Xu, J., Zhou, S.: Flow field analysis of trucks and a design of an additional drag reduction device. Engineering Review, Vol. 38 (2018), Issue 1, 70-78.

[2] Schlichting, G.: Teorija pogranichnogo sloja. Boundary Layer Theory, Moscow (1974). Nauka. 711 p.

[3] Dubau, C.: Resistance and lift coefficients calculation for a turbine blades profiles with horizontal shaft. Journal of Applied Engineering Sciences. 1 (14), (2011), 3, ISSN 2247-3769, pp. 35-40, 2011. 
[4] Dubau, C.: Mathematical modelling on wind turbine blades profiles selection with a horizontal shaft. Journal of Applied Engineering Sciences. 1(14), (2011). 1, ISSN 2247-3769, pp. 61-66.

[5] Dubau C., G.: Calculation of kinematic characteristics throughout the range of conditions to maximize the power extracted from wind in the case of small size turbine. Journal of Applied Engineering Sciences. 2(15), 1, 2012, ISSN 2247-3769, pp. 31-34.

[6] Čarija, Z., Marušić, E., Novak, Z., et al.: Numerical analysis of aerodynamic characteristics of a bumped leading edge turbine blade, Engineering Review, 34 (2014), 2, 93-101.

[7] Kievbus: (2008). http://old.kievbus.info/buses/67- 42021.html

[8] Shelepenkov,M.:http://denisovets.ru/models.html.http://denisovets.ru/laz/lazprototips/LAZ42021_4. jpg

[9] Vozniak, O., T., et al.:. Set for the variable air supply into the conveyance means saloon. Patent of former USSR № 1382674, (1988) BI (bulletin of the inventions).

[10] Voznyak, O., Sukholova, I., Myroniuk, K.: Research of device for air distribution with swirl and spread air jets at variable mode. Eastern European Journal of Enterprise Technologies. 6/7 (78) 2015. pp. $15-23$.

[11] Korbut, V., Voznyak, O., Myroniuk, K., Sukholova, I., Kapalo, P.: Examining a device for air distribution by the interaction of counter non-coaxial jets under alternating mode. Eastern European Journal of Enterprise Technologies. - Vol. 2, No 8 (86) 2017. - pp.30 - 38, ISSN 1729-3774.

[12] Voznyak, O., Myroniuk, K., Dovbush, O.: Relationship between a Person Heat Exchange and Indoor Climate. In Proceedings: Selected scientific Papers. 10th Rzeszow-Lviv-Kosice Conference. Supplementary Issue 2005.Technical University of Kosice. p. $148-152$.

[13] Voznyak, O., Dovbush, O.: Influence of indoor climate on a person heat exchange in a room. In Proceedings: Zeszyty naukowe Politechniki Rzeszowskiej: “Aktualne problemy budownictwa i inżynierii środowiska”. Część 2 - inżynieria środowiska. Rzeszow 2000. - c. 441 - 447.

[14] Vozniak, O., T., et al.: Ventilation hatch for the conveyance means. Patent of ex USSR N1353673, 1987. BI N43 (Bulletin of the inventions).

[15] Voznyak, O., Kovalchuk, A.: Air distribution by opposite non-coaxial air jets. Proceedings paper: VII International Scientific Conference Kosice - Lvov - Rzeszow, 2002. p.173 - 178.

[16] Gorlin, S., M., Slezinger, I., I.: Aeromechanicheskije izmerenija - metody i pribory. Aeromechanical measurements - Methods and Devices. Moscow, 1964. 720p.

[17] Voznyak, O.: Planuvannia eksperymentu ta optymizatsiya vyrishen' u ventyliatsiyniy tehnitsi. (Planning expertise and optimization of ventilation equipment output). Monograph. Lviv (2010): NU "Lvivs'ka Politekhnika" (in Ukrainian), pp. 220.

[18] Voznyy, M., N., Luzinov, N., A.: K otsenke vliyaniya lobovogo soprotivleniya na toplivnuyu ekonomichnost' avtobusov. (To assess the impact of drag on the fuel bus). In the book: VKEIAvtobusproma. (in Russian) Lvov (1981), pp. 8-13. 